ISSN: 2526-7884

Editor: Prof. Dr. Marconi Freitas da Costa Email da revista: cbr@ufpe.br
Avaliação: Double blind review

Recebido: 18 de setembro de 2018

Aceito: 01 de junho de 2018

\title{
ALÉM DOS ALIMENTOS FUNCIONAIS E FITNESS: DESINFORMAÇÃO E DIETA SOB VIÉS EMOCIONAL
}

\author{
Solon Bevilacqua \\ Fernanda Rodrigues Silva \\ Claudia Soares Silva
}

Solon Bevilacqua é Professor da Universidade Federal de Goiás UFG. Email: solbev@gmail.com. Fernanda Rodrigues Silva é Graduada pela Universidade Federal de Goiás - UFG. E-mail: fernandars_94@hotmail.com. Claudia Soares Silva é Graduada pela Universidade Federal de Goiás - UFG. E-mail:

claudia_css@hotmail.com.

Esta pesquisa teve o apoio da

Fundação de Amparo à Pesquisa do Estado de Goiás.

Os autores agradecem aos

avaliadores pelos comentários para melhoria do artigo.

\begin{abstract}
Resumo
Este quase experimento pesquisou as escolhas do consumidor praticante frequente de atividade física no consumo de alimentos funcionais e fitness. Neste experimento natural foi testada a hipótese de que há associação entre os objetivos almejados com uma alimentação suplementar esportiva e a escolha de algumas cestas de produtos. Em três fases (I, II e III), foi questionado o objetivo da alimentação e as escolhas acerca de produtos organizados em opções não identificadas. (I) as cestas "emagrecer", "ganho de massa muscular" e "saúde e bem-estar" não encontraram correspondência frente aos objetivos já declarados. (II) as cestas light, diet, orgânicos e integrais encontraram correspondência parcial na relação com o objetivo: os produtos light e orgânico foram relacionados com objetivos que não correspondiam as suas propriedades. (III) as cestas com 16 produtos foram apresentadas com preço e sem preço. Verificou-se que há fortes evidências para a refutação da hipótese de pesquisa, visto que os participantes da pesquisa não alinharam seus objetivos nutricionais com suas escolhas, suscitando um olhar para efeitos de viés emocional e desinformação.

Palavras-chave: Alimentação suplementar, Desinformação, Atividade esportiva.
\end{abstract}

Esta obra está licenciada com uma Licença Creative Commons Atribuição 4.0 Internacional.

\section{INTRODUÇÃO}

A suplementação alimentar ganhou contornos de destaque junto aos esportistas regulares. Em torno de $30 \%$ do total de praticantes de atividades físicas consome algum tipo de suplemento alimentar (Hirschburch \& 
Carvalho, 2008). Seu consumo pode minimizar o desgaste causado por exercícios intensos, repor as perdas ou ainda melhorar a performance (Kreider, Miriel, \& Bertum, 2009). Não se trata de um medicamento, tampouco de um alimento (Da Justa Neves \& Caldas, 2015), sendo consumido num ambiente de desinformação e de escassas medidas regulatórias (Gabriels \& Lambert, 2013).

Inseridos num ambiente de promessas e de fortes pressões mercadológicas, tem-se ainda questões comportamentais e culturais envolvidas, que conferem complexidade ao universo dos produtos funcionais $\mathrm{e}$ suplementares. É possível relacionar, por exemplo, a dificuldade para antever um futuro de ganhos obtidos a partir de uma dieta do presente. Em meio ao stress, dedicação e esforço do treino físico, o consumidor de alimentos suplementar e funcional deve visualizar seus ganhos em descompassos conhecidos como desconto intertemporal (Hsee, Loewenstein, \& Blount, 1999) e lacuna da empatia (Loewenstein, 2000).

A partir do exposto, este estudo delimita-se na lacuna entre $\mathrm{o}$ consumo cultural $\mathrm{e}$ comportamental, num contexto em que o consumidor não segue a regra racional das preferências estáveis e maximização dos ganhos. A hipótese de pesquisa a ser testada é que há associação entre os objetivos almejados com uma alimentação suplementar esportiva e a escolha de algumas cestas de produtos (ganho de massa, emagrecimento e bem-estar, além de light, diet, orgânico e integral). Após a instalação do tema e objetivo, tem-se a seguir o detalhamento da proposta metodológica. A pesquisa contribui para políticas públicas e mercado quando sugere que haja mais rigor com as informações para especificações e consumo; quando indica que mais estudos sejam realizados e para uma agenda futura de pesquisas no âmbito da economia comportamental, principalmente no que se refere ao viés de escolhas (Smith, Stoddard, \& Barnes, 2009).

\section{DISCUSSÃO TEÓRICA}

Quando se analisa a alimentação de praticantes de atividades físicas no Brasil, a partir de alguns estudos isolados, tem-se que há um consumo não saudável relacionada à ingestão de alimentos e suplementos (Rossi et al., 2011). Alimentos como carboidratos complexos, fibras e leite são consumidos em nível abaixo do desejado. Acrescenta-se ao fato um baixo consumo de fibras, vitaminas e minerais, postos em segundo plano quando do consumo de alimentos industrializados (BrandMiller, Holt, Pawlak, \& McMillan, 2002). Tais constatações apresentam-se como conectores a outro fato evidenciado nesse estudo: uma alimentação equivocada de suplementos e alimentos funcionais, a despeito do elevado nível de escolaridade dos consumidores.

0 fato parece se agravar quando em contraste com outros estudos, que expandem as análises para grupos como o de adolescentes (Braggion, Matsudo, \& Matsudo, 2000). Se por um lado temos indivíduos que buscam uma vida mais jovem; bem estar e redução de algumas doenças; por outro lado temos práticas agressivas de comercialização e ausências de leis que regulamentem as práticas mercadológicas. Não se espera, por exemplo, que alimentos funcionais venham em cápsulas ou industrializados de outras formas. Inseridos nesse contexto há um número considerável de pessoas que frequentam regularmente academias e consomem suplementos sem orientação especializada, possivelmente sem necessidade (Aguilera, 2016).

Mas as escolhas relacionadas ao consumo de alimentação suplementar são influenciadas por outros fatores, além das questões da desinformação e ações mercadológicas que incentivam o consumo. Há uma série de aspectos comportamentais que podem ser relacionados às escolhas desse consumidor.

0 primeiro aspecto comportamental a ser indicado é a inconsistência temporal (Readl \& Loewenstein, 1995). Esse viés para as escolhas ocorre quando um indivíduo, no presente, não prediz acertadamente quais serão suas preferências no futuro. No caso específico do consumo de alimentos, a pessoa teria dificuldade em adotar uma dieta saudável no presente, em função da dificuldade de antever ganhos de saúde e bem estar no futuro. Nessa situação, não se trata de considerar unicamente uma falta de autocontrole com a alimentação adequada, tampouco na pressão exercida pela mídia dos fast food que impõe dietas pobres, mas que a cultura influencia a dieta e a dieta influencia a saúde. Parece um exercício razoável 
considerar a viabilidade de várias combinações de prática cultural e saúde pública (Smith, 2004).

A questão é reforçada em estudos relacionados. De acordo com um experimento posto em prática com participantes norte americanos, o ganho de peso estaria relacionado às quatro medidas de insegurança econômica (probabilidade de desemprego, número de quedas de renda, volatilidade de renda e probabilidade ficar pobre) (Smith, Stoddard, \& Barnes, 2009). Questões como a inconsistência dinâmica, variação genética, suscetibilidade à intervenção farmacêutica e variação sazonal, status socioeconômico e grau de segurança financeira também devem ser considerados incentivadores da obesidade (Smith, 2009). Estaria, portanto, a pobreza relacionada a obesidade. 0 conjunto de fatores indica que fazer uma dieta ou render-se ao ganho de peso, deve receber especial atenção nos estudos comportamentais, pois a questão não prevê apenas trade offs para sabores, preços e quantidades.

Dispor produtos isolados ou em grupos também apresenta viés para as escolhas. Se alimentos fossem dispostos num conjunto de amostras e, em outra situação fossem apresentados um a um, certamente as escolhas não seriam as mesmas. A questão reside na hipótese que é mais difícil avaliar a conveniência dos valores em alguns atributos do que em outros (Hsee, Loewenstein, \& Blount, 1999). Acrescenta-se a problemática a teoria da "lacuna da empatia", quando estados "quentes", como emoções associadas a altos níveis de excitação (por exemplo, raiva ou medo), estados de sensibilidade (por exemplo, dor) e estados de impulso (por exemplo, sede, vontade intensa relacionada a um vício, excitação sexual) entram em ação perturbando as escolhas (Loewenstein, 2000).

Diante do exposto, é possível sugerir que diante das múltiplas razões apresentadas, a escolha correta de um suplemento para cada objetivo nutricional, esteja permeada por inúmeros vieses - que variam da desinformação, pressão da mídia, alimentação desbalanceada e principalmente, heurísticas, vieses cognitivos potencializados pela condição especial deste consumo de produtos funcionais e suplementares.

\section{MATERIAL E MÉTODO}

\section{Sujeito}

A escolha pelo participante desse estudo recaiu em praticantes frequentes de atividade física. Foram investigados 60 participantes ao todo, divididos em dois grupos. Adotou-se como critério de inclusão aqueles praticantes de atividade física que frequentassem academias três vezes por semana, no mínimo, além de serem consumidores de algum tipo de suplemento ou alimentação funcional. A abordagem para a pesquisa foi realizada em duas academias de Goiânia, em dois momentos distintos: antes e após o treino.

Quadro 1 - Quadro Resumo 'Cestas de Consumo’

\begin{tabular}{|c|l|}
\hline Fase 1 & $\begin{array}{l}\text { Confronto entre objetivos com alimentação e três cestas de produtos. Investigou-se os objetivos de } \\
\text { os participantes no consumo das cestas 'emagrecer', 'ganho de massa' e 'saúde e bem estar'. Os } 16 \\
\text { produtos foram organizados afim de compor as } 3 \text { cestas. Os participantes indicavam objetivos e } \\
\text { quais cestas estavam alinhadas a seus objetivos. }\end{array}$ \\
\hline Fase 2 & $\begin{array}{l}\text { Confronto de objetivos com alimentação e produtos light, diet, orgânicos e integrais. Nesta fase as } \\
\text { cestas foram organizadas de acordo com esta nova classificação. Novamente os participantes } \\
\text { foram questionados acerca de novas escolhas. }\end{array}$ \\
\hline Fase 3 & $\begin{array}{l}\text { Confronto de objetivos com alimentação e cestas de produtos com preços. A fase 2 da pesquisa foi } \\
\text { relançada com preços para os produtos Goji Berry, BCAA, farinha de berinjela, chá verde, } \\
\text { glutamina, cacau, chá de Hibiscus, Whey Protein, Ômega 3, L-Carnitina, pasta de amendoim, óleo } \\
\text { de coco, albumina e sementes diversas. }\end{array}$ \\
\hline
\end{tabular}

Fonte: Elaborado pelos autores.

\section{Delineamento}

0 desenvolvimento da pesquisa previu três fases relacionadas ao "declarado e revelado" dos participantes, descritas a seguir. As declarações dos participantes evidenciam o seu objetivo no consumo. As revelações são 
fornecidas pelas análises e indicam se há relação entre o que as declarações e as revelações nas análises.

A coleta de dados foi realizada no sudeste goiano, entre o período de 15 de junho de 2016 a 22 de julho de 2016, junto a três academias de musculação, luta, dança e outros. Os participantes eram abordados na entrada e saída da academia, convidados a avaliarem as cestas dispostas numa mesa e, a seguir indicarem suas escolhas. Previamente informavam seus objetivos com a nutrição esportiva suplementar.

Os objetivos desse consumo são aqueles previstos no quadro 2:

Quadro 2 - Os Objetivos

\begin{tabular}{|ll|}
\hline 1. & Reduzir o percentual de gordura; \\
\hline 2. & Aumentar a saciedade; \\
\hline 3. & Diminuir a retenção de líquidos no organismo; \\
\hline 4. & Aumentar o gasto energético do organismo; \\
\hline 5. & Reposição proteica; \\
\hline 6. & Reparação muscular; \\
\hline 7. & Aumentar a massa muscular; \\
\hline 8. & Reduzir a fadiga muscular; \\
\hline 9. & Aumentar a energia durante o dia; \\
\hline 10. & Fortalecer o sistema imunológico; \\
\hline 11. & Reduzir o mau colesterol; \\
\hline 12. & Melhorar o trânsito intestinal; \\
\hline 13. & Combater o envelhecimento precoce; \\
\hline 14. & Evitar a osteoporose; \\
\hline 15. & Evitar doenças cardíacas. \\
\hline & Fonte: Elaborado pelos autores. \\
\hline
\end{tabular}

Após questões como frequência de consumo e aspectos de idas a nutricionistas, eram apresentadas três cestas contendo produtos funcionais e suplementares.

As perguntas realizadas questionaram objetivos com o treino e com a alimentação suplementar; frequência de treinos e quais cestas são preferidas.

\section{Fase I: Cestas Emagrecer, Ganho Massa Muscular e Saúde}

Foi questionado sobre o objetivo quando da nutrição esportiva aos praticantes frequentes de atividade física. Registravam-se os objetivos e a seguir eram apresentadas as cestas contendo os produtos relacionados no quadro3. Para a composição das cestas de consumo foram feitas consultas a um nutricionista esportivo, especialista em suplementação esportiva.

Os grupos foram definidos em virtude do agrupamento de possíveis objetivos, como emagrecimentos, ganho de massa magra, saúde e bem estar. A meta dessa etapa é apontar a coerência entre o objetivo e o conhecimento no consumo de produtos funcionais e suplementares. As cestas não eram identificadas com objetivos.

Quadro 3 - Três Cestas

\begin{tabular}{|l|l|l|}
\hline \multicolumn{1}{|c|}{ Emagrecer } & \multicolumn{1}{c|}{ Ganho Massa Muscular } & \multicolumn{1}{c|}{ Saúde e Bem-Estar } \\
\hline GOJI BERRY & BCAA & FARINHA DE \\
\hline CHÁ VERDE & GLUTAMINA & CACAU \\
\hline CHÁ DE & WHEY PROTEIN & ÔMEGA 3 \\
\hline L-CARNITINA & PASTA DE AMENDOIM & ÓLEO DE COCO \\
\hline & ALBUMINA & SEMENTES \\
\hline
\end{tabular}

Fonte: Elaborado pelos autores. 


\section{Fase II: Cestas Light, Diet, Orgânicos e Integrais}

Foi questionado aos participantes acerca de suas escolhas de alimentação suplementar e funcional. As respostas possíveis eram produtos light, diet, orgânicos e integrais. Nesta fase os participantes declaravam se consideravam o consumo desse tipo de produto como "muito importante; "importante"; "pouco importante" e "sem importância." A seguir, novamente ele indicava a cesta que continha tais produtos (light, diet, orgânicos e integrais). As respostas eram tabuladas em planilha específica.

\section{Fase III: Cestas Emagrecer, Ganho Massa Muscular e Saúde com preços}

Nessa fase os participantes escolhiam produtos que continham a indicação de light, diet, orgânico e integral em suas embalagens, acrescidas de seus preços de mercado. Foi realizada uma pesquisa de preços em lojas de suplementos e estipulado um preço médio.

\section{Técnica de análise de Dados}

0 procedimento de análise de dados consistiu em análise de distribuição de frequência e aplicação do teste de MannWhitney para amostras não pareadas. 0 teste foi adotado por se tratar de um exame envolvendo dados não paramétricos e amostras pareadas e, nesse caso, a análise da mediana revelou-se mais precisa como medida de posição ao invés do emprego da média.

\section{Análise de Variáveis Estranhas}

Em consideração às variáveis espúrias, considerou-se três possibilidades para variáveis que interferissem nas análises: marca dos produtos; tempo de desenvolvimento da pesquisa e aleatoriedade. Buscou-se conceder as mesmas oportunidades para os participantes, bem como evitar marcas regionais $\mathrm{e}$ consagradas. 0 quase experimento foi desenvolvido rapidamente para assegurar que o fator tempo não interviesse.

\section{ANÁLISE DOS DADOS}

Com relação ao perfil da amostra, os participantes eram predominantemente do sexo masculino $(60,78 \%)$; de 23 a 28 anos $(23,53 \%)$ e 28 a 33 anos (33,33\%); e graduados em algum curso superior $(66,67 \%)$; renda predominante de $\mathrm{R} \$ 1.000,00$ a $\mathrm{R} \$ 3.000,00$ (37,25\%). Quando questionados se realizavam algum tipo de dieta alimentar, 72,55\% dos participantes afirmaram de forma positiva. Realizam atividades físicas de 3 a 4 vezes por semana $(43,13 \%)$ e de 5 a 6 vezes por semana $(35,29 \%)$.

A amostra também se caracterizou por ser bem informada com relação a busca de informações alimentares. Um percentual significativo busca informações junto a nutricionistas ou médicos $(54,50 \%)$. Quanto à frequência de consumo de produtos light, diet, orgânico e integral, afirmaram que consomem 4 vezes por semana produtos light $(50,98 \%) ; 1$ vez por semana produtos $\operatorname{diet}(31,37 \%) ; 2$ vezes por semana produtos Orgânicos $(45,10 \%)$ e 2 vezes por semana produtos Integrais $(47,06 \%)$.

Quando questionados sobre o que levam em consideração no momento da compra de produtos saudáveis, afirmaram que priorizam as informações nutricionais $(35,09 \%)$; prazo de validade (47,06\%) e sugestão de amigos $(27,54 \%)$ e marca $(27,54 \%)$. Os principais objetivos almejados com uma alimentação suplementar ou funcional é reduzir o percentual de gordura $(71,43 \%)$ e reduzir a fadiga muscular (71,43\%). 0 número de citações é superior ao número de observações devido às respostas múltiplas (15 no máximo). Esses dados representam os aspectos declarados da pesquisa.

\section{Fase I}

A primeira fase da pesquisa contemplou a apresentação de produtos em três cestas que agrupavam itens de acordo com os objetivos "perder peso"; "ganhar massa magra" e "bem estar". Constatou-se que as cestas escolhidas estavam em desacordo com os objetivos indicados. Os produtos escolhidos não correspondiam aos objetivos almejados. Os participantes atribuiam uma nota para a cesta a ser escolhida. Tal aspecto foi observado nos grupos da experiência e no de controle.

Grupo de Controle: cestas identificadas com objetivos.

Grupo Experimental: cestas não identificadas com os objetivos. 
Em consideração a uma análise prévia dos dados declarados e revelados da pesquisa, temse que os participantes possuíam um elevado nível de escolaridade; praticam atividades físicas com regularidade (esse seria um critério de inclusão do estudo); estavam convictos de seus objetivos enquanto consumidores de suplementos e alimentos funcionais e buscavam informações sobre nutrição junto a médicos e nutricionistas, entretanto a prática revelou-se outra. A análise do p-value $(0,0001)$ indicou forte diferença entre as medianas obtidas.

\section{Fase II}

As considerações do estudo preveem que o consumidor de produtos suplementares e funcionais não alinha seus objetivos com suas práticas de consumo, além de não ter um conhecimento definido do que é light, diet, orgânico e integral. Cabe ressaltar que o participante se revelou na maioria dos casos um pesquisador para seu consumo, visto que além da busca por nutricionistas e médicos, realiza pesquisas em sites especializados e busca as melhores marcas. A motivação está centrada na busca por uma vida mais jovem por parte dos mais velhos e o bem estar (Roberfroid, 2000).

A partir dos dados, tem-se que maior preocupação relaciona-se com a redução do percentual de gordura $(71,43 \%)$; a redução da fadiga muscular (71,43\%); e a redução do mau colesterol $(47,62 \%)$ como objetivos primários. Os dados revelam a busca pela perda de peso e demais problemas relacionados, afinal a busca por um produto suplementar ou funcional parece abrir outras portas para o consumo de mais suplementos e recursos (Nichter \& Thompson, 2006). Desvelam também outro aspecto presente no estudo de (Chiou, Yang, \& Wan, 2011): 0 consumo de suplementos fez com que atletas se voltem ao consumo hedônico, bem como à preferência por alimentos nada naturais ao invés de alimentação orgânica. Os dados também se alinham à questão da diversidade de interesses relacionada à escolha de produtos suplementares que exige segmentação específica para idade, gênero e comportamento, além de sabor, conveniência e variedade (Ares \& Gámbaro, 2007). A partir do quadro 4 percebe-se que o produto light não está relacionado a um dos três objetivos propostos. É considerado pouco importante para todos os casos. Aqui se revela um desvio frente às propriedades desses alimentos, afinal um produto light, deveria prever as seguintes questões:

O consumidor deve ficar atento também para os alimentos que são considerados light, pois, além da redução de, pelo menos, $25 \%$ do nutriente, esta redução deve significar, no mínimo, uma quantidade absoluta do mesmo. No caso de alimento sólido, por exemplo, no que se refere ao valor calórico, que é o caso mais comum, o valor total da redução deve ser, no mínimo, de 40 calorias para cada $100 \mathrm{~g}$ de alimento e para os líquidos esse valor deve ser, no mínimo, de 20 calorias para cada $100 \mathrm{ml}$. Nem todo alimento light é próprio para emagrecimento (Inmetro, 2017).

Quadro 4 - Cruzamento de Cesta Light versus Objetivos

\begin{tabular}{|l|c|c|c|c|}
\hline \multicolumn{1}{|c|}{ Cesta Light } & Emagrecer & $\begin{array}{c}\text { Ganho de } \\
\text { Massa }\end{array}$ & Saúde & Total \\
\hline Muito Importante & $11,11 \%$ & $0,00 \%$ & - & $4,00 \%$ \\
\hline Importante & $11,11 \%$ & $25,00 \%$ & - & $8,00 \%$ \\
\hline Pouco Importante & $66,67 \%$ & $50,00 \%$ & $83,33 \%$ & $72,00 \%$ \\
\hline Sem Importância & $11,11 \%$ & $25,00 \%$ & $16,67 \%$ & $16,00 \%$ \\
\hline Total & $100 \%$ & $100 \%$ & $100 \%$ & $100 \%$ \\
\hline
\end{tabular}

Fonte: Elaborado pelos autores.

Quando do cruzamento de cesta diet com objetivos, percebe-se que os produtos Diet são vistos como não importante para saúde e emagrecimento, conforme o quadro 5 . Em consideração a definição prevista pelo Inmetro as escolhas se apresentaram alinhadas aos conceitos (Inmetro, 2017).

De acordo com essa legislação, o termo diet pode, opcionalmente, ser utilizado em alimentos produzidos para indivíduos com 
exigências físicas e/ou que sofrem de doenças específicas como, por exemplo, Diabetes. Nesses casos podem ser incluídos alimentos indicados para as dietas com restrição dos nutrientes: carboidrato, gordura, proteínas e sódio - alimentos exclusivamente empregados para controle de peso - alimentos para dieta de ingestão controlada de açúcar. 0 termo light, por sua vez, pode, opcionalmente, ser utilizado em alimentos produzidos de forma que sua composição reduza em, no mínimo, 25\% o valor calórico e os seguintes nutrientes: açúcares, gordura saturada, gorduras totais, colesterol e sódio comparado com o produto tradicional ou similar de marcas diferentes. Portanto, com a retirada ou redução de algum nutriente, o alimento pode apresentar uma diminuição de calorias, e o consumidor que deseja emagrecer deve estar atento à tabela nutricional, que é obrigatória para estes produtos, e verificar se esta redução é significativa e justifica a substituição do alimento convencional pelo diet ou light, que costumam ser mais caros que os convencionais.

Quadro 5 - Cruzamento de Cesta Diet versus Objetivos

\begin{tabular}{|l|c|c|c|c|}
\hline \multicolumn{1}{|c|}{ Cesta Diet } & Emagrecer & $\begin{array}{c}\text { Ganho de } \\
\text { Massa }\end{array}$ & Saúde & Total \\
\hline Muito Importante & - & - & - & - \\
\hline Importante & $11,11 \%$ & $25,00 \%$ & $16,67 \%$ & $16,00 \%$ \\
\hline Pouco Importante & $22,22 \%$ & $25,00 \%$ & $8,33 \%$ & $16,00 \%$ \\
\hline Sem Importância & $66,67 \%$ & $50,00 \%$ & $75,00 \%$ & $16,00 \%$ \\
\hline Total & $100 \%$ & $100 \%$ & $100 \%$ & $100 \%$ \\
\hline
\end{tabular}

Fonte: Elaborado pelos autores.

O terceiro cruzamento consistiu em analisar os produtos orgânicos e objetivos. Ganho de Massa e Saúde despontam como os principais objetivos entre os praticantes de atividades físicas, conforme percebido a partir do quadro 6. De acordo com o Ministério da Agricultura um produto orgânico deve ter as seguintes características:

Para ser considerado orgânico, o produto tem que ser produzido em um ambiente de produção orgânica, onde se utiliza como base do processo produtivo os princípios agroecológicos que contemplam o uso responsável do solo, da água, do ar e dos demais recursos naturais, respeitando as relações sociais e culturais.

Nesta tabulação o ganho de massa não representa um objetivo no consumo orgânico frente à definição proposta pelo ministério da agricultura.

Quadro 6 - Cruzamento de Cesta Orgânica versus Objetivos

\begin{tabular}{|l|c|c|c|c|}
\hline \multicolumn{1}{|c|}{ Cesta Diet } & Emagrecer & $\begin{array}{c}\text { Ganho de } \\
\text { Massa }\end{array}$ & Saúde & Total \\
\hline Muito Importante & $44,44 \%$ & $75,00 \%$ & $75,00 \%$ & $64,00 \%$ \\
\hline Importante & $22,22 \%$ & - & $16,67 \%$ & $16,00 \%$ \\
\hline Pouco Importante & $11,11 \%$ & $25,00 \%$ & - & $8,00 \%$ \\
\hline Sem Importância & $22,22 \%$ & $0,00 \%$ & $8,33 \%$ & $12,00 \%$ \\
\hline Total & $100 \%$ & $100 \%$ & $100 \%$ & $100 \%$ \\
\hline
\end{tabular}

Fonte: Elaborado pelos autores.

A última tabulação cruzada consistiu em analisar o cruzamento entre produtos integrais e os objetivos com uma alimentação vista como fitness. As maiores preocupações com esse tipo de alimentação é a busca de saúde e emagrecimento, conforme o quadro 7. De acordo com o Ministério da Saúde (2016) "Estudos e pesquisas comprovam cada vez mais que os alimentos integrais fazem muito bem à saúde. As fibras contidas nos alimentos integrais aumentam a sensação de saciedade e ajudam no funcionamento do intestino, fundamental para a saúde e o bem-estar".

A figura 1 apresenta um quadro resumo de todos os cruzamentos e os graus de importância atribuídos a cada cesta de compra. 
Figura 1 - Grau de Importância

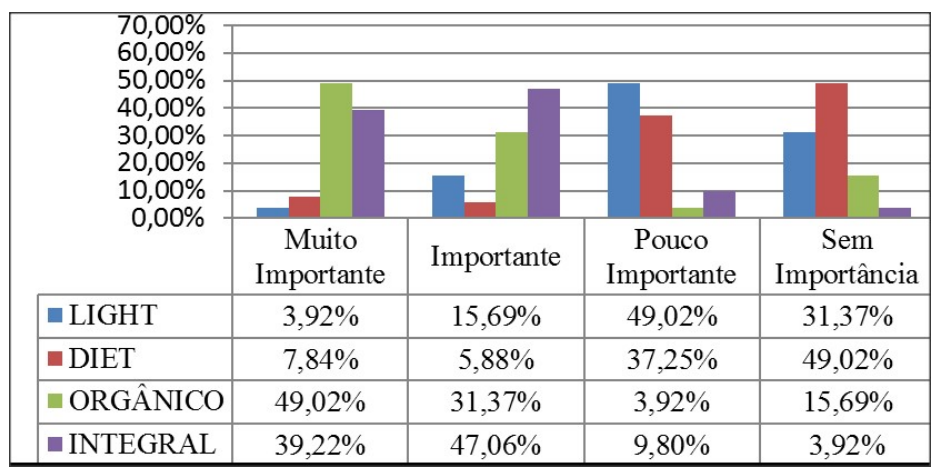

Fonte: Elaborado pelos autores.

Seria, portanto um benefício indireto de seu consumo, a perda de peso e um ganho direto, a saúde e o bem-estar. São, basicamente, grãos e cereais (arroz, trigo, aveia e centeio e seus derivados farelo, farinha e pão), que não passaram por nenhum processo de refinação. 0 quadro 7 indica que os participantes consideram o emagrecimento um fator mais importante do que a saúde.

Quadro 7 - Cruzamento de Cesta Integral versus Objetivos

\begin{tabular}{|l|c|c|c|c|}
\hline \multicolumn{1}{|c|}{ Cesta Diet } & Emagrecer & $\begin{array}{c}\text { Ganho de } \\
\text { Massa }\end{array}$ & Saúde & Total \\
\hline Muito Importante & $44,44 \%$ & $25,00 \%$ & $25,00 \%$ & $32,00 \%$ \\
\hline Importante & $56,56 \%$ & $50,00 \%$ & $66,67 \%$ & $60,00 \%$ \\
\hline Pouco Importante & - & - & $8,33 \%$ & $4,00 \%$ \\
\hline Sem Importância & - & $25,00 \%$ & $0,00 \%$ & $4,00 \%$ \\
\hline Total & $100 \%$ & $100 \%$ & $100 \%$ & $100 \%$ \\
\hline
\end{tabular}

Fonte: Elaborado pelos autores.

Considerando os principais cruzamentos, entende-se que os produtos light são percebidos para ganho de massa; os produtos light são consumidos para emagrecimento e busca de saúde; os produtos orgânicos são vistos como insumos de ganho de massa e saúde e, finalmente, os produtos integrais, são consumidos para saúde e emagrecimento.

\section{Fase III}

Nessa etapa do estudo foram apresentados vários produtos sem preço, primeiramente, com a indicação nas embalagens de orgânico, diet, integral e light. 0 participante escolhia os produtos de acordo com seus objetivos. Esperava-se um alinhamento total entre objetivos e produtos, considerando que a embalagem já fornecia a informação nos rótulos para essa classificação. Considera-se, portanto, a hipótese (Hp) como "os objetivos encontram-se alinhados com as escolhas".

A última etapa da pesquisa previu apresentar o preço para os participantes realizarem suas escolhas. Conforme pode ser constatado no quadro 8 , as alterações não foram significativas a ponto de rejeitar a hipótese nula, ou seja, o preço não se apresenta preponderante para que o consumidor de suplementos e alimentos funcionais altere suas escolhas.

Quadro 8 - Análise Geral

\begin{tabular}{|l|c|c|c|c|}
\hline \multicolumn{1}{|c|}{ Produto } & Tipo & Marca & Preço & $p$-value \\
\hline Açúcar Demerara 1 kg & orgânico & Native & 10,90 & 0,705 \\
\hline Arroz Premium 1kg & integral & Zaeli & 4,99 & 0,154 \\
\hline Aveia em flocos & integral & Quaker & 3,15 & 0,157 \\
\hline
\end{tabular}




\begin{tabular}{|l|c|c|c|c|} 
Banana com chocolate & orgânico & Monama & 10,90 & 0,655 \\
\hline Barra de cereal & light & Mundo verde & 1,20 & 0,109 \\
\hline Barra de cereal Quinoa & orgânico & Bio2 & 2,90 & 0,465 \\
\hline Biscoito frutas vermelhas & integral & Yoki & 3,19 & 0,151 \\
\hline Cappuccino $150 \mathrm{~g}$ & diet & 3 Corações & 9,35 & 0,109 \\
\hline Cookies & integral & Mae terra & 2,50 & 0,153 \\
\hline Cookies $150 \mathrm{~g}$ & diet & Jasmine & 6,90 & 0,090 \\
\hline Gelatina de Morango & diet & Dr. Oetker & 2,09 & 0,109 \\
\hline Geleia 200g & diet & Doces São Lourenço & 10,90 & 0,655 \\
\hline Macarrão Speciale Penne & integral & Santa Amália & 5,09 & 0,317 \\
\hline Nescau & light & Nestle & 11,25 & 0,155 \\
\hline Requeijão 200g & light & Canto de minas & 4,29 & 0,109 \\
\hline Torrada 160g & light & Bauducco & 3,49 & 0,156 \\
\hline Tribos azeite \& ervas & orgânico & Mãe terra & 2,90 & 0,705 \\
\hline Vinagre de fruta maça 250 ml & orgânico & Rosani & 13,90 & 0,285 \\
\hline
\end{tabular}

Fonte: Elaborado pelos autores.

A chance dessas 18 diferenças entre as médias ser devido ao acaso (e não um efeito dos tratamentos) varia de $10,90 \%$ a $70,50 \%$. Em outras palavras, se as diferenças entre as medianas ocorreram por causa dos tratamentos, este intervalo registra as chances de existir um engano.

Figura 2 - Preços e valores para o p-value.

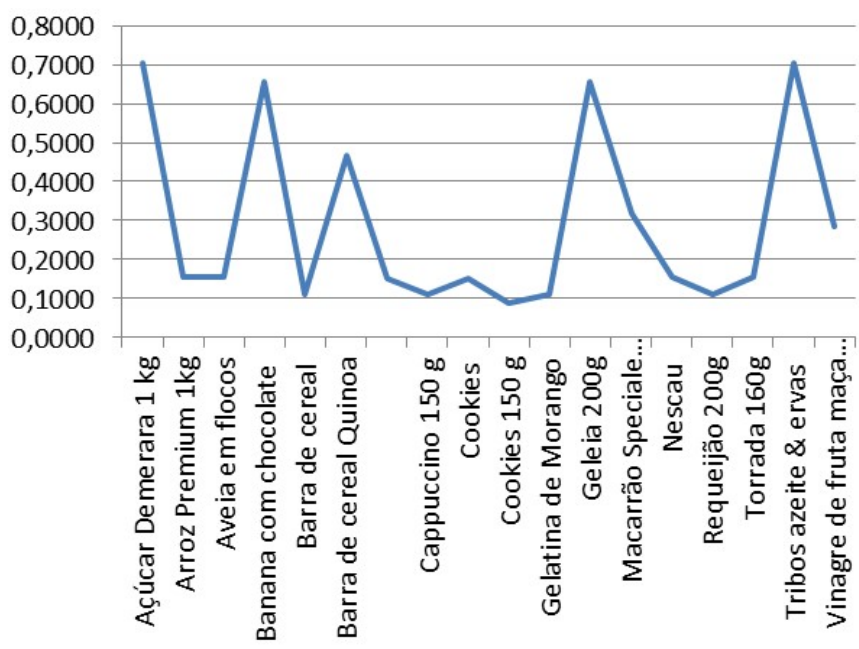

Fonte: Elaborado pelos autores.

As possiblidades 'próximas' para rejeição da hipótese nula são os produtos cookies $150 \mathrm{~g}$ (diet), barra de cereal (light), cappuccino 150g (diet), gelatina de morango (diet), requeijão $200 \mathrm{~g}$ (light). Os produtos com valores de pvalue mais altos foram os seguintes:

Banana com chocolate (orgânico), Geleia 200g (diet), Açúcar Demerara 1 kg (orgânico), Tribos Azeite \& Ervas (orgânico). Os produtos que teriam mudanças verificadas nas duas etapas do último teste foram diet ou light e, aqueles que não teriam alterações nas suas mudanças de preços, foram os orgânicos.

As cestas de produtos foram apresentadas aos indivíduos a partir de um modelo que contempla variáveis centradas na busca de maximização da utilidade, tais como preço, benefícios e variedade, mas os valores elevados para o $p$-value sugerem uma inconstância nas escolhas, além de impossibilidade de refutar-se a HP. 
O comportamento das escolhas observadas na figura 2 apresenta uma tendência para ausência de respostas em virtude da falta de padrões. Em Skinner (1953) tem-se que esta é uma característica importante da análise do comportamento: a habilidade de esperar por uma resposta combinada com uma busca contínua de explicação e a rejeição de explicações prematuras. Trata-se de uma disposição para aceitar fatos, mesmo quando eles se opõem aos desejos. Sem dúvida, novos estudos centrados nas emoções deste consumo, são imperativos, tais como agrupamento de produtos versus produtos separados (Hsee, Loewenstein, \& Blount, 1999); lacunas de empatia ou estados 'quente e frio' (Loewenstein, 2000) ou ainda as forças sociais (Ávila \& Bianchi, 2015), são sugestivos para o entendimento dos trade offs ora apresentados.

\section{CONSIDERAÇÕES FINAIS}

Nesse estudo ao ser testado o conhecimento do consumidor de alimentos funcionais e fitness constatou-se que há desinformação no consumo de alimentos para "perder peso"; "ganhar massa magra" e "bem-estar", mesmo com a indicação de médicos e nutricionistas. Os participantes são instruídos e de renda média a elevada e, buscam uma silhueta mais magra e redução da fadiga muscular. Os ganhos de bem estar e saúde não são considerados como prioridade.

0 estudo I evidenciou que os produtos diet não são vistos como agentes para a perda de peso e os alimentos orgânicos e light são consumidos de forma acertada. No que se refere aos orgânicos, há uma predileção para seu consumo para ganho de massa. O estudo II evidenciou que os produtos integrais são vistos como agentes do bem-estar e da saúde, mas há um maior interesse pelo seu consumo para a perda de peso. Finalmente, o estudo III apresentou uma manipulação do preço e tal procedimento conferiu mudanças insignificantes para as escolhas, ou seja, o preço não é determinante no processo de escolha de alimentos fitness e funcionais. Perder peso e reduzir a fadiga muscular é prioridade neste universo de consumo.

Rótulos são lidos para verificar o prazo de validade dos produtos, que são comprados sem que o preço exerça um papel preponderante nas escolhas. Entretanto os produtos orgânicos sugerem que se houver alteração nos preços as escolhas não irão se alterar. Já nos produtos light e diet, existindo variações nos preços, as escolham mudam. 0 consumidor dessa classe de produtos é sensível a preço, já como os pertencentes aos demais grupos não o são.

As três cestas de consumo; os 17 produtos suplementares; objetivos declarados e as escolhas foram testadas neste quase experimento. A hipótese de pesquisa que previa indicar a associação entre os objetivos almejados com uma alimentação suplementar esportiva e a escolha de algumas cestas de produtos não se confirmou, visto que o $p$-value para os 17 itens investigados ficou acima de 0,100 .

Tais achados, em contraste com pesquisas recentes (Fung, Murawski, \& Bode, 2017), evidenciam que o entendimento das escolhas alimentares (suplementares, funcionais e outras) deve ter suporte na utilidade descontada, quando trade offs explícitos envolvem custos e benefícios. São opções que envolvem o prazer imediato do paladar e as consequências futuras à saúde (Smith, 2004); relacionam praticantes de dieta que supostamente precisam de alguma forma de imediatizar os custos da satisfação atual (Herman \& Polivy, 2003).

Os achados desta pesquisa sugerem continuidades nos pressupostos da economia comportamental. Estudar os trade offs para alimentação suplementar exige alguns entendimentos como consumo pré e pós treino; dificuldade em prever os ganhos futuros quando do consumo de suplementação (inconsistência temporal); complexidade nas escolhas entre produtos isolados e agrupados, entre outros.

Ademais, inúmeros casos, presentes nos estudos de economia comportamental, por exemplo, poderiam ser relacionados a estes resultados. Seria possível ilustrar, como os estados "quentes" de consumo (Loewenstein, 2000), quando fatores viscerais, como emoções (dor, stress, tensão e cansaço pós treino) podem alterar as escolhas.

\section{REFERÊNCIAS}

Aguilera, C. R. (2016). Consumo, características y perfil del consumidor de suplementos 
nutricionales en gimnasios de Santiago de Chile. Revista Andaluza de Medicina del Deporte, 9(3), 99-104.

Ares, G., \& Gámbaro, A. (2007). Influence of gender, age and motives underlying food choice on perceived healthiness and willingness to try functional foods. Appetite, 49(1), 148-158.

Ávila, F., \& Bianchi, A. M. (2015). Guía de Economía Comportamental e Experimental. São Paulo: Economia Comportamental.org.

Braggion, G. F., Matsudo, S. M., \& Matsudo, V. R. (2000). Consumo alimentar, atividade física e percepção da aparência corporal em adolescentes. Revista Brasileira de Ciência e Movimento, 15-21.

Brand-Miller, J. C., Holt, S. H., Pawlak, D. B., \& McMillan, J. (2002). Glycemic index and obesity. Am J Clin Nutr, 1, 28-38.

Chiou, W.-B., Yang, C.-C., \& Wan, C.-S. (2011). Ironic effects of dietary supplementation illusory invulnerability created by taking dietary supplements licenses health-risk behaviors. Psychological Science, 1081-1086.

Da Justa Neves, D. B., \& Caldas, E. D. (2015). Dietary supplements: International legal framework and adulteration profiles, and characteristics of products on the Brazilian clandestine market. Regulatory Toxicology and Pharmacology, 73, 9.

Fung, B., Murawski, C., \& Bode, S. (2017). Caloric primary rewards systematically alter time perception. Journal of Experimental Psychology, 1925.

Gabriels, G., \& Lambert, M. (2013). Nutritional supplement products: does the label information influence purchasing decisions for the physically active? Nutritional Journal, 12(1), 100-121.

Herman, C. P., \& Polivy, J. (2003). Dieting as an exercise in behavioral economics. In: G. F. Loewenstein, \& D. Read, Time and decision:economic and psychological perspectives on intertemporal choice (pp. 459489). New York: Russell Sage Foundation.

Hirschburch, M., \& Carvalho, J. (2008). O que é ser um nutricionista esportivo. Nutrição Esportiva: uma visão prática. Barueri: Manole.
Hsee, C. K., Loewenstein, G. F., \& Blount, S. \&. (1999). Preference reversals between joint and separate evaluations of options: a review and theoretical analysis. Psychological Bulletin, 576.

Inmetro. (18 de fevereiro de 2017). Instituto Nacional de Metrologia, Qualidade $e$ Tecnologia. Acesso em 20 de fevereiro de 2017, disponível em Inmetro: http://www.inmetro.gov.br/

Kreider, R. B., Miriel, V., \& Bertum, E. (2009). Aminoacid supplementation and exercise performance. Sports Medicine, 190-209.

Loewenstein, G. (2000). Emotions in economic theory and economic behavior. The American Economic Review, 426-432.

Ministério da Saúde. (20 de dezembro de 2016). Portal da Saúde. Acesso em 20 de dezembro de 2016, disponível em Portal da Saúde: http://portalsaude.saude.gov.br/

Readl, D., \& Loewenstein, G. (1995). Diversification bias: Explaining the discrepancy in variety seeking between combined and separated choices. Journal of Experimental Psychology: Applied, 34.

Roberfroid, M. (2000). Concepts and strategy of functional food science: the European perspective. The American journal of clinical nutrition. 71(6), 1660-1664.

Rossi, L., Hayashi, A. P., Solis, M. Y., Lugaresi, R., Almeida, N., Szarfarc, S. C., \& Philippi, S. T. (2011). Avaliação qualitativa e quantitativa do consumo alimentar de mulheres fisicamente ativas. Mundo Saúde, 35(2), 179-184.

Skinner, B. F. (1953). Science and Human Behavior. New York, Macmillan, p. 13.

Smith, T. (2004). The McDonald's Equilibrium. Advertising, empty calories, and the endogenous determination of dietary preferences. Social Choice \& Welfare, 31.

Smith, T. (2009). Reconciling psychology with economics: Obesity, behavioral biology, and rational overeating. Journal of Bioeconomics, 249-282.

Smith, T., Stoddard, C., \& Barnes, M. (2009). Why the Poor Get Fat: Weight Gain and economy insecurity. Forum for Health Economics \& Policy, 12(2), 31.

\title{
Beyond Functional Foods and Fitness: Disinformation and Diet Under Emotional Bias
}

\begin{abstract}
This quasi-experiment researched the choices of the frequent practicing consumer of physical activity in the consumption of functional foods and fitness. In this natural experiment, the hypothesis was tested that there is an association between the objectives pursued with a supplementary sports diet and the choice of some baskets of products. In three phases (I, II and III), the objective of feeding and the choices
\end{abstract}


about products organized in unidentified options were questioned. (I) the baskets "slimming", "gain of muscle mass" and "health and well-being" did not find correspondence in front of the stated objectives. (II) light, diet, organic and integral baskets found partial correspondence in relation to the objective: light and organic products were related to objectives that did not correspond to their properties. (III) baskets with 16 products were presented with price and without price. It was found that there is strong evidence for the refutation of the research hypothesis, since the research participants did not align their nutritional goals with their choices, raising a glance for the effects of emotional bias and misinformation.

Keywords: Supplementary feeding, Misinformation, Sport activity. 